Ärztliche Erfahrung beschränkt sich nicht auf medizinisches Fachwissen.

\title{
„Aber nein, Frau Doktor, ich schlafe doch nicht!"
}

\begin{abstract}
- Als ich die Tür zum Seniorenzentrum öffnete, kam mir eine angenehme, kühle Luft entgegen, die mich sofort beruhigte. Meine erste Patientin war Frau Forst.
\end{abstract}

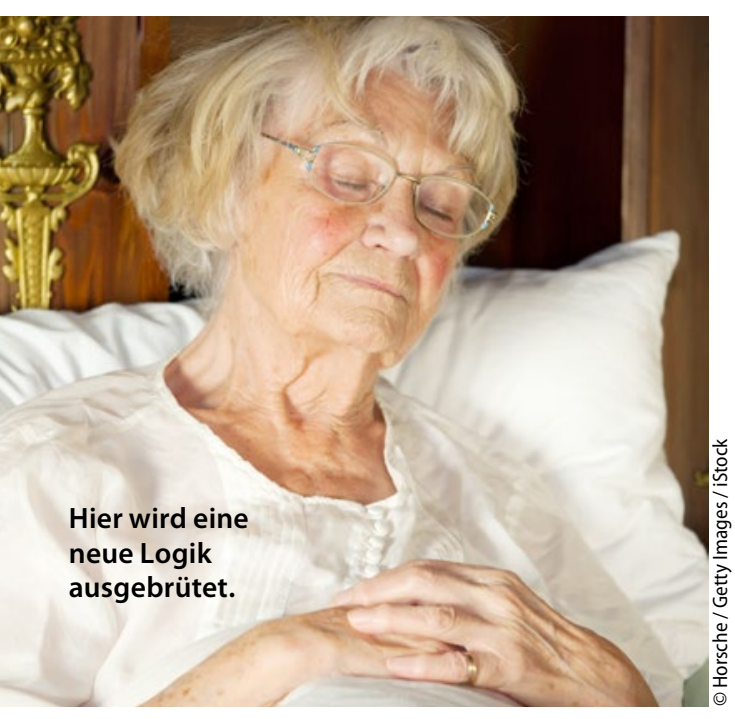

Auf mein Anklopfen reagierte sie nicht. Das war öfter so, denn sie war schwerhörig. Ich betrat vorsichtig die Wohnung, um sie nicht zu erschrecken. Meine Patientin lag in ihrem Bett auf dem Rücken und hielt die Hände ineinander verschränkt auf dem Bauch. Ihre Augen waren geschlossen, und ihr Kopf versank in dem großen Federkissen. Aus ihrem leicht geöffneten Mund drang ein leises Schnarchen - sie schlief.

Um diese Ruhe beneidete ich sie. Ich dachte an die stressige Sprechstunde in meiner Arztpraxis am Vormittag und die zehnminütige Mittagspause, in der ich es geschafft hatte, zu essen und nebenbei die Laborbefunde des Tages zu kontrollieren. Nach den Hausbesuchen warteten ein voller Schreibtisch und eine dicht bestellte Nachmittagssprechstunde auf mich. Eine Auszeit oder Schlaf waren für die nächsten Stunden nicht geplant.
Vorsichtig strich ich meiner Patientin über den Arm: „Frau Forst, aufwachen!“ Sie öffnete abrupt die Augen und schaute mich an. Als sie mich erkannte, lächelte sie und atmete erleichtert auf. „Sie haben geschlafen“, erklärte ich. „Ich musste Sie wecken." Sie schüttelte energisch ihren Kopf. „Nein, ich habe nicht geschlafen, nur nachgedacht."

Nachdenken ist schlafen?

Nanu?

Der Satz meiner Patientin schwirrte mir während der übrigen Hausbesuche durch den Kopf. Aber auf der Rückfahrt vom Seniorenzentrum zur Praxis fand ich meinen inneren Frieden. Ich freute mich auf meine nächste Sprechstunde. Da muss man nämlich viel nachdenken - gemäß der Logik von Frau Frost konnte ich mich also auf eine exzellente Schlafgelegenheit freuen.

Dr. Simone Braune, Wolfsburg

\section{Bei Heilerde sind Mensch und Tier sich einig}

_ Langsam kamen die Patienten aus den Ferien zurück. Manche hatten weniger erfreuliche Urlaubsandenken mit nach Hause gebracht. Ganz oben auf der Liste: der exotische Magen-Darm-Infekt. Montezumas Rache. Unsere späte Quittung für die Vergehen der Spanier. Oder jedenfalls so ähnlich.

So kam auch eine Privatpatientin zu mir, die nach entsprechenden Sympto- men leicht besorgt um ihre Gesundheit war. Sie hatte sich einen Virusinfekt eingefangen, nichts Schlimmes, Aber sie litt immer noch, und wollte bald wieder fit für den Alltag sein.

Ich verordnete ihr für ein paar wenige Tage Omeprazol und Heilerde. „Oh, prima“, kommentierte sie - dafür müsste sie weder zur Apotheke noch zum Reformhaus. „Das Omeprazol kann ich ganz einfach von meinem Mann nehmen“, meinte sie. „Und die Heilerde von meinem Hund!"

Als sie am nächsten Tag vereinbarungsgemäß anrief, ging es ihr schon viel besser. Aber die Heilerde fand sie scheußlich. Nachdenklich fügte sie an: "Jetzt kann ich aber wenigstens meinen armen Hund verstehen ..."

Dr. Luise Hess, Darmstadt 